Western University

Scholarship@Western

Aboriginal Policy Research Consortium International (APRCi)

2007

\title{
Indigenous and Non-Indigenous Child Oral Health in Three Australian States and Territories
}

Lisa M. Jamieson

Follow this and additional works at: https://ir.lib.uwo.ca/aprci

Citation of this paper:

Jamieson, Lisa M., "Indigenous and Non-Indigenous Child Oral Health in Three Australian States and Territories" (2007). Aboriginal Policy Research Consortium International (APRCi). 380.

https://ir.lib.uwo.ca/aprci/380 
This article was downloaded by: [University of Western Ontario]

On: 18 November 2012, At: 07:00

Publisher: Routledge

Informa Ltd Registered in England and Wales Registered Number: 1072954 Registered

office: Mortimer House, 37-41 Mortimer Street, London W1T 3J H, UK

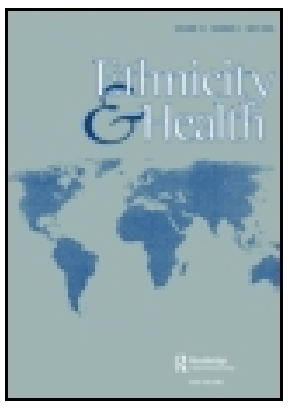

\section{Ethnicity \& Health}

Publication details, including instructions for authors and subscription information:

http:// www.tandfonline.com/loi/ ceth20

\section{Indigenous and Non-Indigenous Child Oral Health in Three Australian States and Territories}

Lisa M. J amieson, Jason M. Armfield \& Kaye F. Roberts-Thomson Version of record first published: 19 J an 2007.

To cite this article: Lisa M. J amieson, J ason M. Armfield \& Kaye F. Roberts-Thomson (2007): Indigenous and Non-Indigenous Child Oral Health in Three Australian States and Territories, Ethnicity \& Health, 12:1, 89-107

To link to this article: http:// dx.doi.org/ 10.1080/ 13557850601002197

\section{PLEASE SCROLL DOWN FOR ARTICLE}

Full terms and conditions of use: http://www.tandfonline.com/page/terms-andconditions

This article may be used for research, teaching, and private study purposes. Any substantial or systematic reproduction, redistribution, reselling, loan, sub-licensing, systematic supply, or distribution in any form to anyone is expressly forbidden.

The publisher does not give any warranty express or implied or make any representation that the contents will be complete or accurate or up to date. The accuracy of any instructions, formulae, and drug doses should be independently verified with primary sources. The publisher shall not be liable for any loss, actions, claims, proceedings, demand, or costs or damages whatsoever or howsoever caused arising directly or indirectly in connection with or arising out of the use of this material. 


\title{
Indigenous and Non-Indigenous Child Oral Health in Three Australian States and Territories
}

\author{
Lisa M. Jamieson, Jason M. Armfield \& \\ Kaye F. Roberts-Thomson
}

Objectives. To explore the prevalence and severity of Indigenous and non-Indigenous child dental disease in relation to age, sex, residential location and socio-economic status in three Australian states and territories.

Design. Children aged 4-14 years who were enrolled in a school dental or screening service in New South Wales, South Australia and the Northern Territory, Australia, were randomly selected to take part in this cross-sectional study. Bivariate and multivariate analyses were used to assess outcomes.

Results. A total of 328,042 children were included, of which 10,517 (3.2\%) were Indigenous. Some $67.1 \%$ of Indigenous children lived in rural areas and $47.3 \%$ lived in areas of high disadvantage. About 37.5\% of 4- to 10-year-old Indigenous children had no experience of dental disease in the primary dentition while $70.7 \%$ of 6- to 14-year-old Indigenous children had caries-free permanent dentitions. The mean number of decayed, missing and filled primary teeth (dmft) of Indigenous 4- to 10-year-old children was 2.9 $(S D$; 3.4) while the mean DMFT of Indigenous 6- to 14-year-old children was 0.8 (SD; 1.6). Across all age-groups, Indigenous children living in the most deprived areas had higher dmft and DMFT levels than their more socially advantaged counterparts, while rural-dwelling Indigenous children had higher levels of dental disease experience than metropolitan-dwelling Indigenous children. After adjusting for potential confounding, Indigenous children aged 4-10 years were over twice as likely to have caries in the deciduous dentition than similarly aged non-Indigenous children (OR: 2.25, CI: 2.142.36), and 6- to 14-year-old Indigenous children were over one and a half times more

\footnotetext{
Correspondence to: Lisa M. Jamieson, Australian Research Centre for Population Oral Health, The University of Adelaide, South Australia 5005, Australia. Tel: +6188303 4611; Fax: +61 88303 4858; Email: lisa.jamieson@adelaide.edu.au
} 
likely to have decay in the permanent dentition (OR: 1.68, CI: 1.60-1.77) than their non-Indigenous counterparts.

Conclusion. Indigenous children experienced higher caries prevalence and severity than non-Indigenous children, irrespective of other socio-demographic factors. Factors concerning Indigenous social capital may have influenced our findings.

Keywords: Indigenous; Children; Dental Caries; Socio-economic Status; Rurality

\section{Introduction}

Indigenous people in Australia are those who identify as Aboriginal, Torres Strait Islander or both (ABS 2003). They lived for an estimated 50,000 years in all areas of the continent prior to European settlement in 1788, after which their numbers were reduced by $90 \%$ (largely due to introduced diseases; Broome 2002). From the late 1830s remnants of Indigenous groups were moved onto remotely located reserves and missions and during the 1900s, separation of Indigenous children from their families was an official Government policy (Broome 2002). Today, many Indigenous people are unfamiliar with their origins and this, together with the ongoing effects of poverty, discrimination and racism, has contributed to the rapid unravelling of a once robust society (NHC 2001).

Indigenous children aged $0-14$ years represent $4.7 \%$ of the Australian child population (ABS 2001a). They are not equally distributed throughout the nation, however, with almost 30\% residing in New South Wales and only $1 \%$ living in the Australian Capital Territory (Figure 1). While 52\% of Indigenous children live in metropolitan areas, the Indigenous proportion of the total child population increases with rising geographic remoteness, with $25 \%$ of Indigenous children living in

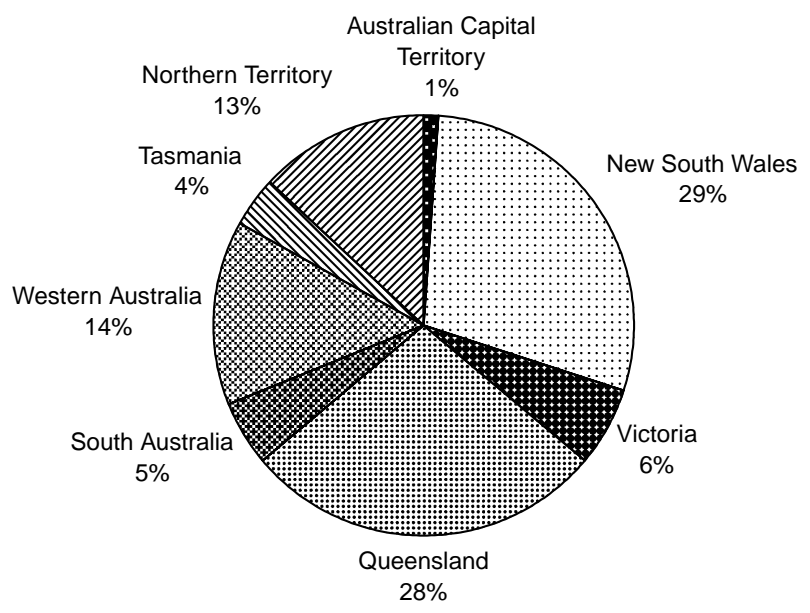

Figure 1 Proportion of Indigenous Children by Australian State/Territory (ABS 2001a). 
'remote' or 'very remote' areas compared with 3\% of their non-Indigenous counterparts (ABS 2003). The relative impoverishment of Indigenous children also increases with increasing remoteness, with housing becoming less robust, and water and social services less reliable (Thomson 2003).

Increasing exposure to non-Indigenous lifestyles has impacted on Indigenous child general health. Indigenous children are at higher risk of disease and injury than other Australian children and are more likely to be hospitalised for most conditions (AIHW 2004). They experience greater disability and reduced quality of life due to ill health, partake in higher levels of health risk behaviours (for example, petrol sniffing) and are more exposed to violence in the home. They are also more than twice as likely to have been born underweight than other Australian children (AIHW 2004), with low birth weight babies being more prone to ill health, including dental ill health, in later life (Kuh \& Ben-Shlomo 1997; Nicolau et al. 2003). In 2002, Indigenous child mortality rates were 2.7 times those of non-Indigenous children (AIHW 2004).

The lifestyle upheavals experienced by Indigenous Australians have also had a marked impact on Indigenous oral health, particularly child oral health. Traditionally, Indigenous children were recognised as having better oral health than their nonIndigenous counterparts (Barrett 1953; Kailis 1971a,b; Barrett \& Williamson 1972) but recent evidence suggests that Indigenous children now have, on average, twice as much (and in some communities, up to five times as much) dental caries (tooth decay) as non-Indigenous children (Schamschula et al. 1980; Bourke et al. 1999; Tennant et al. 2000; Endean et al. 2004). In one study of remote Indigenous children, more than $90 \%$ of child dmfs (the sum of decayed, missing and filled deciduous surfaces) was found to be made up of either decayed or missing surfaces, and less than $10 \%$ of tooth surfaces with experience of decay had been treated with a filling (Bourke et al. 1999).

The purpose of this paper is to describe the oral health status of Indigenous and non-Indigenous children in three Australian states and territories by age, sex, residential location and socio-economic status (SES). The paper is the first to provide population-based estimates of dental disease prevalence and severity of Indigenous and non-Indigenous child populations in three geo-political areas of Australia. The findings provide some insight into the complex and interrelated factors that influence Indigenous and non-Indigenous child oral health disparities.

\section{Methods}

Data were obtained from the Child Dental Health Survey; a national oral health investigation of children enrolled in the School Dental Service (SDS) in each Australian state and territory. Children were enrolled from public and private schools, and examinations were conducted by dental health professionals employed by the SDS. Dental examiners were not calibrated, but received similar training and used standardised procedures. Indigenous status data were collected for all children except 
those from Western Australia, Tasmania and the Australian Capital Territory. The small numbers of Indigenous children sampled in Victoria and the poor compliance with the collection of Indigenous status in Queensland meant that these states were unable to provide reliable statistics.

For the purposes of our investigation, analyses of the oral health of Indigenous and non-Indigenous children were therefore confined to collections from New South Wales, South Australia and the Northern Territory. At the time of collection in New South Wales, the SDS employed a targeted state-wide program that involved screening children every two years from kindergarten through to Year 8 (ages 4-13 years). A full enumeration of New South Wales children was included. In South Australia, a full enumeration of children was also obtained, with surface level tooth data captured using their $\mathrm{EXACT}^{\mathrm{TM}}$ treatment charting and management information system. In the Northern Territory, a random sampling procedure was used to select approximately one in two (1:1.9) children residing in the capital city of Darwin. This was achieved by selecting children whose birthday was between the 1st and 16th (inclusive) of any given month. All children residing outside the capital city of Darwin were included.

All data were weighted on the basis of 'area of sampling' and 'sampling fraction' to provide a more representative result, and by 'time since last dental examination' so that children on longer recall intervals were not under-represented (children with no dental health concerns are placed on 15-18 month recall). Unit records were further weighted to reflect the estimated resident population (ERP) of 4-14 year olds in New South Wales, South Australia and the Northern Territory, respectively, according to the Australian Bureau of Statistics (ABS). Ethical approval for the study was obtained from the Australian Institute of Health and Welfare and the University of Adelaide.

\section{Socio-economic Status Index}

The Socio-Economic Indices For Areas (SEIFA; ABS 2001b) were used to determine SES. Developed by the ABS, the indices use data derived from the 2001 Census of Population and Housing and employ a range of measures to rank areas based on their relative social and economic well-being. For purposes of this paper, the SEIFA Index of Disadvantage (category 2) was used. This index takes into account variables relating to income, educational attainment, unemployment and dwellings without motor vehicles. In particular it focuses on low-income earners, relatively lower educational attainment and high unemployment. The SEIFA Index has been validated against household measures of SES (ABS 2001b) and is a standardised instrument frequently used in the measurement of SES at a population level in Australia. In the figures, ' 1 ' denotes the most disadvantaged areas and ' 4 ' denotes the least disadvantaged areas. 


\section{Location Index}

The Rural, Remote and Metropolitan Areas (RRMA) classification was used to measure location. The classification is based on Statistical Local Areas (SLA) and allocates each SLA in Australia to a category based primarily on population numbers and an index of remoteness. The classification was defined by the then Commonwealth Department of Primary Industry and Energy, and Human Services and Health in 1994 based on 1991 Census data. For purposes of our study, rural and remote zones were combined.

\section{Oral Health Index}

The dmft (sum of decayed, missing and filled teeth in the deciduous dentition) and DMFT (sum of decayed, missing and filled teeth in the permanent dentition) indices were used to assess oral health outcomes. The indices are a cumulative measure of caries experience that express the amount of successfully treated disease (filled teeth), unsuccessfully treated disease (extracted teeth) and untreated disease (decayed teeth). They include a record of the presence/absence of all teeth including presumptive cause of tooth loss. Both measures were used for children aged 6-10 years because in such age-groups children have a mixed dentition (both primary and permanent teeth are present). Permanent teeth usually begin erupting around the age of five or six years.

Caries prevalence $(\mathrm{dmft} / \mathrm{DMFT}>0)$ and severity (mean $\mathrm{dmft} / \mathrm{DMFT}$ ) were calculated from data collected over a 12-month period; 2000 for New South Wales, 2002 for the Northern Territory and 2003 for South Australia. When children received more than one examination during any given calendar year, information derived only from the first examination was included.

Data were analysed using SPSS 12.0 and levels of statistical significance were set at $p<0.05$. The Pearson Chi-square test was used to compare differences in proportions and analysis of variance (ANOVA) when the dependent variable was continuous. Non-parametric tests were used if data were not normally distributed; the MannWhitney U-test for two independent variables and the Kruskal-Wallis test for more than two comparison groups. The presence of dental caries in the deciduous and permanent dentition was modelled using logistic regression, with socio-demographic variables significant in the bivariate analyses entered as independent variables. These were: age $(4-7$ years old $=1,8-11$ and $12-14$ years old $=0)$, sex $($ male $=1$, female $=$ 0 ), Indigenous status (Indigenous $=1$, non-Indigenous $=0$ ), residential location (rural $=1$, metropolitan $=0$ ) and SES (most disadvantaged $=1$, other three levels of disadvantage $=0)$.

\section{Results}

The distribution of Indigenous and non-Indigenous children by state/territory and ERP is presented in Table 1. Just over $12 \%$ of New South Wales Indigenous children 
Table 1 Distribution of 4- to 14-Year-Old Indigenous and Non-Indigenous Children by State/Territory and Estimated Resident Population $(\mathrm{ERP})$

\begin{tabular}{|c|c|c|c|c|c|c|c|c|c|}
\hline & $\begin{array}{l}\text { Indigenous } \\
\text { sample }(n)\end{array}$ & $\begin{array}{l}\text { Indigenous } \\
\operatorname{ERP}(n)\end{array}$ & $\begin{array}{l}\text { Proportion } \\
\text { Indigenous } \\
\text { sample in In- } \\
\text { digenous } \\
\text { ERP }(\%)\end{array}$ & $\begin{array}{l}\text { Non-Indi- } \\
\text { genous sam- } \\
\text { ple }(n)\end{array}$ & $\begin{array}{l}\text { Non-Indi- } \\
\text { genous ERP } \\
(n)\end{array}$ & $\begin{array}{l}\text { Proportion } \\
\text { non-Indigen- } \\
\text { ous sample in } \\
\text { non-Indigen- } \\
\text { ous ERP }(\%)\end{array}$ & $\begin{array}{c}\text { Total sample } \\
(n)\end{array}$ & $\begin{array}{l}\text { Total ERP } \\
(n)\end{array}$ & $\begin{array}{c}\text { Proportion } \\
\text { total sample } \\
\text { in total ERP } \\
(\%)\end{array}$ \\
\hline New South Wales & 4,376 & 35,509 & 12.3 & 244,271 & 870,674 & 28.1 & 248,647 & 906,183 & 27.4 \\
\hline South Australia & 1,678 & 6,538 & 25.7 & 65,072 & 192,476 & 33.8 & 66,750 & 199,014 & 33.5 \\
\hline Northern Territory & 4,463 & 13,480 & 33.1 & 8,182 & 19,728 & 41.5 & 12,645 & 33,208 & 38.1 \\
\hline Total & 10,517 & 55,527 & 23.7 & 317,525 & $1,082,878$ & 34.5 & 328,042 & $1,138,405$ & 33.0 \\
\hline
\end{tabular}


were included in our sample, over one-quarter of South Australian Indigenous children and one-third of Indigenous children in the Northern Territory. Our overall sample $(n=328,042)$ represented one-third of the total 4 - to 14-year-old ERP of New South Wales, South Australia and the Northern Territory combined. Some 10,517 (3.2\%) children were Indigenous.

The socio-demographic and dental characteristics of the sample by Indigenous status are presented in Table 2. Forty-six per cent of Indigenous children were aged 8-11 years, while $41.2 \%$ of non-Indigenous children were in the same age-group. There were more females than males in both Indigenous and non-Indigenous groups.

Table 2 Socio-demographic and Dental Characteristics by Indigenous Status (Column Percentages in Parentheses)

\begin{tabular}{|c|c|c|}
\hline & Indigenous & Non-Indigenous \\
\hline Total & $10,517(3.2)$ & $317,525(96.8)$ \\
\hline \multicolumn{3}{|l|}{$\operatorname{Age}^{\mathrm{a}}$} \\
\hline $4-7$ years & $4,182(39.8)$ & $130,856(41.2)$ \\
\hline $8-11$ years & $4,839(46.0)$ & $130,704(41.2)$ \\
\hline $12-14$ years & $1,496(14.2)$ & $55,965(17.6)$ \\
\hline \multicolumn{3}{|l|}{$\operatorname{Sex}^{\mathrm{b}}$} \\
\hline Male & $5,102(48.5)$ & $147,871(46.6)$ \\
\hline Female & $5,410(51.5)$ & $169,508(53.4)$ \\
\hline \multicolumn{3}{|l|}{ Residential location ${ }^{\mathrm{b}}$} \\
\hline Metropolitan & $3,450(32.9)$ & $229,964(72.9)$ \\
\hline Rural & $7,023(67.1)$ & $85,662(27.1)$ \\
\hline \multicolumn{3}{|l|}{ Socio-economic disadvantage ${ }^{\mathrm{b}}$} \\
\hline 1 (Most disadvantaged) & $4,947(47.3)$ & $75,283(24.0)$ \\
\hline 2 & $3,180(30.5)$ & $107,905(34.7)$ \\
\hline 3 & $1,769(17.0)$ & $61,446(19.8)$ \\
\hline 4 (Least disadvantaged) & $532(5.1)$ & $66,002(21.1)$ \\
\hline Caries-free deciduous $(4-10 \text { years })^{\mathrm{b}}$ & $2,893(37.5)$ & $139,601(62.8)$ \\
\hline Caries-free permanent $(6-14 \text { years })^{\mathrm{b}}$ & $6,133(70.7)$ & $210,139(81.3)$ \\
\hline \multicolumn{3}{|l|}{$\begin{array}{l}\text { Mean number of decayed, missing and } \\
\text { filled deciduous teeth (SD) }\end{array}$} \\
\hline$(4-10 \text { years })^{c}$ & $2.86(3.40)$ & $1.40(2.49)$ \\
\hline \multicolumn{3}{|l|}{$\begin{array}{l}\text { Mean number of decayed, missing and } \\
\text { filled permanent teeth (SD) }\end{array}$} \\
\hline$(6-14 \text { years })^{\mathrm{c}}$ & $0.75(1.60)$ & $0.46(1.23)$ \\
\hline
\end{tabular}

${ }^{\mathrm{a} C h i}$-square test: $p<0.01$.

${ }^{\mathrm{b}}$ Chi-square test: $p<0.001$.

${ }^{\mathrm{c}}$ Mann-Whitney U-test: $p<0.001$. 
Over two-thirds of Indigenous children lived in rural locations, compared with less than $30 \%$ of non-Indigenous children. Almost half (47.3\%) the Indigenous children were in the most disadvantaged SES category, compared with less than one-quarter (24.2\%) of their non-Indigenous counterparts. Less than $40 \%$ of 4 - to 10 -year-old Indigenous children were caries-free in the deciduous dentition compared with over $60 \%$ of similarly aged non-Indigenous children, and just over $70 \%$ of 6 - to 14 -yearold Indigenous children were caries-free in the permanent dentition, compared with just over $80 \%$ of their similarly aged non-Indigenous counterparts. The mean $\mathrm{dmft}$ of 4- to 10-year-old Indigenous children was twice that of similarly aged nonIndigenous children, and the mean DMFT of 6- to 14-year-old Indigenous children was 1.6 times that of their 6- to 14-year-old non-Indigenous counterparts.

The mean dmft of 4- to 10-year-old Indigenous and non-Indigenous children by the SEIFA Index of Relative Disadvantage is presented in Figure 2. The numbers of Indigenous children in the least disadvantaged category across each age-group were too small to allow for robust statistical analyses, and were thus excluded. Indigenous children across all age-groups had higher $\mathrm{dmft}$ than non-Indigenous children, and Indigenous children in the most disadvantaged category had higher dmft than Indigenous children who were less disadvantaged. Disadvantaged Indigenous children aged four to six years had the highest $\mathrm{dmft}$ scores, and this was around 2.5 times the dmft of four- to six-year-old disadvantaged non-Indigenous children. The dmft differential among Indigenous and non-Indigenous children decreased with increasing age, although across all age-groups the $\mathrm{dmft}$ of the most advantaged Indigenous children was less than the $\mathrm{dmft}$ of the most disadvantaged nonIndigenous children. The mean $\mathrm{dmft}$ of non-Indigenous children decreased with increasing social advantage across all age-groups. The highest $\mathrm{dmft}$ level of nonIndigenous children was observed among six to eight year olds.

The mean DMFT of 6- to 14-year-old Indigenous and non-Indigenous children by the SEIFA Index of Relative Disadvantage is presented in Figure 3. Due to small sample sizes, Indigenous children in the least disadvantaged category were not included in the analyses. Across all age-groups, Indigenous children had higher DMFT than non-Indigenous children and this differential increased with increasing age. Indigenous and non-Indigenous children in the most disadvantaged SES category had higher DMFT than their counterparts in more advantaged categories across all age-groups, with mean DMFT decreasing with increasing social advantage. The highest DMFT was observed among Indigenous 14 year olds in the most disadvantaged category, and this was 1.6 times the DMFT of similarly disadvantaged non-Indigenous 14 year olds. The greatest DMFT differential among disadvantaged Indigenous and non-Indigenous children was observed among 10 year olds (10-yearold disadvantaged Indigenous children had 2.1 times the DMFT of their disadvantaged non-Indigenous counterparts). Across all age-groups (except nine years), Indigenous children in the least disadvantaged categories had higher DMFT than the most disadvantaged non-Indigenous children. 


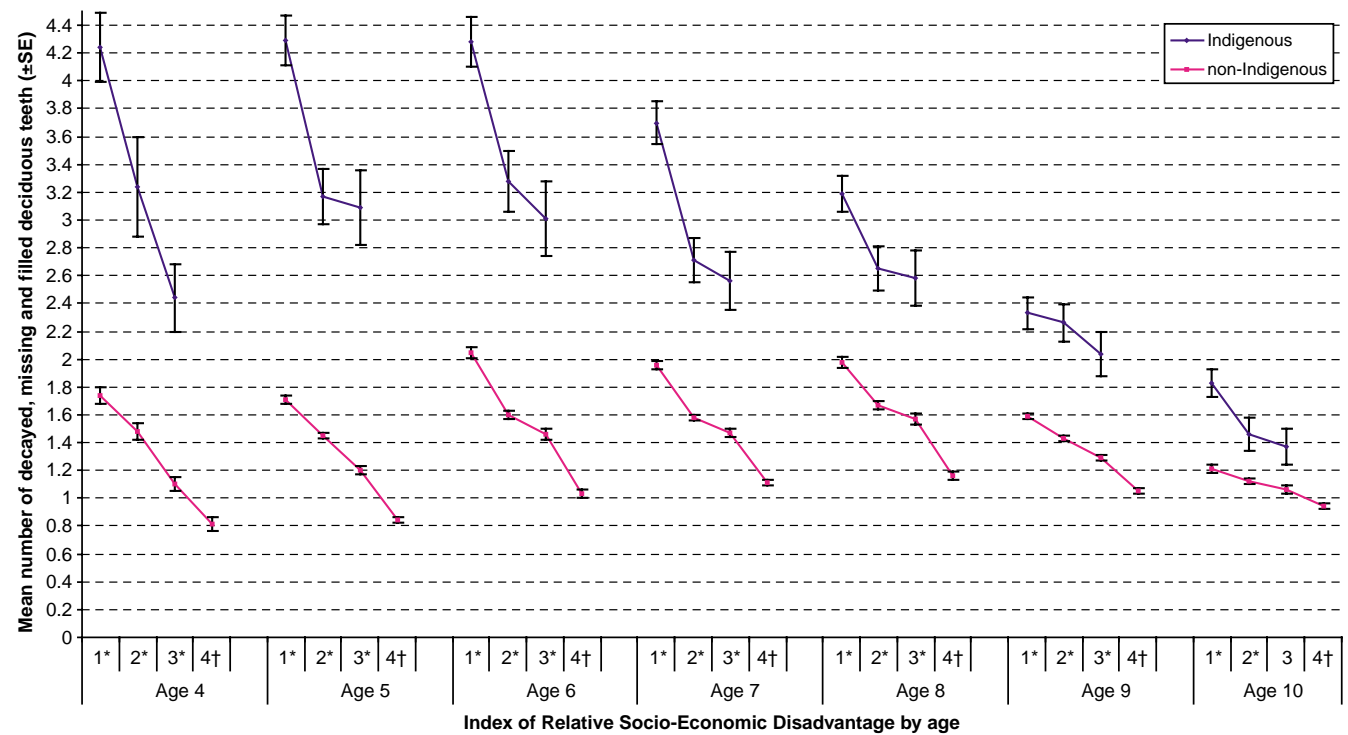

Figure 2 Mean Number of Decayed, Missing and Filled Deciduous Teeth of 4- to 10-Year-Old Children by Index of Relative Socio-economic Disadvantage $(1=$ Most Socially Disadvantaged and $4=$ Least Socially Disadvantaged $) .{ }^{\star} p<0.05$. $\dagger$ Estimates with a Relative Standard Error $>40 \%$ Excluded. 


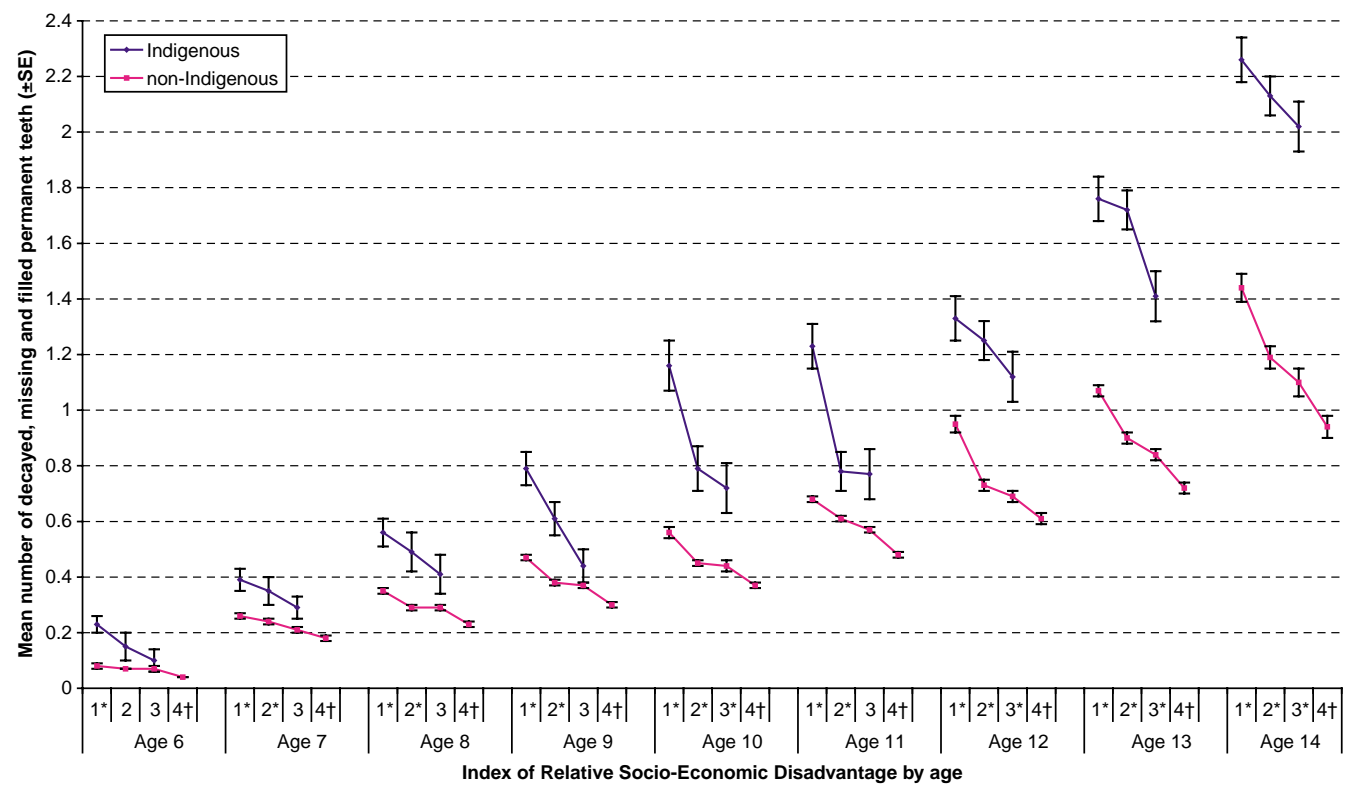

Figure 3 Mean Number of Decayed, Missing and Filled Permanent Teeth of 6- to 14-Year-Old Children by Index of Relative Socio-economic Disadvantage $(1=$ Most Socially Disadvantaged and $4=$ Least Socially Disadvantaged $) .{ }^{\star} p<0.05$. $†$ Estimates with a Relative Standard Error $>40 \%$ Excluded. 
The mean $\mathrm{dmft}$ of 4 - to 10 -year-old Indigenous and non-Indigenous children by residential location is presented in Figure 4. In all age-groups, remote Indigenous children had the highest mean dmft levels followed by metropolitan Indigenous children, rural non-Indigenous children and metropolitan non-Indigenous children. Rural Indigenous children aged five to six years had the highest dmft levels, and these were 2.5 and 2.3 times those of similarly aged rural non-Indigenous children, respectively. The greatest $\mathrm{dmft}$ differential between rural Indigenous and nonIndigenous children was observed among four year olds, with four-year-old rural Indigenous children having 2.6 times the $\mathrm{dmft}$ of rural non-Indigenous four year olds. The mean dmft generally decreased with increasing age across Indigenous groups, with the trend being most marked among rural Indigenous children.

The mean DMFT of 6- to 14-year-old Indigenous and non-Indigenous children by residential location is presented in Figure 5. Indigenous children had higher DMFT than non-Indigenous children across all age-groups, with the differential becoming more marked with increasing age. Across all age-groups, rural Indigenous children had greater DMFT than their metropolitan counterparts but rural and metropolitan non-Indigenous DMFT levels were relatively similar. The highest DMFT was observed among rural Indigenous 14 year olds, and this was 1.9 times that of rural nonIndigenous 14 year olds. The greatest DMFT differential between rural Indigenous and non-Indigenous children was observed among six year olds, with six-year-old rural Indigenous children having 3.6 times the DMFT of rural non-Indigenous six year olds. The mean DMFT increased with increasing age for all children, with the steepest gradient occurring among rural Indigenous children.

The logistic regression model for the presence of caries in the deciduous teeth of 4-10 year olds is presented in Table 3 . Indigenous children were more than twice as likely to have caries experience in the primary dentition than non-Indigenous children. Children aged four to seven years had over one and a half times the odds of caries presence than children aged $8-11$ and $12-14$ years, respectively. The odds of caries presence in the deciduous dentition were almost one and a half times greater for rural-dwelling or socially disadvantaged children, respectively. Being male was also associated with dental caries presence, with males being 1.14 times more likely to have experienced dental disease in the deciduous dentition than females. The Nagelkerke $R$-square statistic for the model was 0.030 .

The logistic regression model for the presence of caries in the permanent teeth of 6-14 year olds is presented in Table 4. Indigenous children were over one and a half times more likely than non-Indigenous children to have caries experience in the permanent dentition. Socially disadvantaged children were 1.3 times more likely to have dental decay than those more economically fortunate, and rural-dwelling children had marginally higher odds (1.04) of having caries in the permanent dentition than their urban-dwelling counterparts. Being male was negatively associated with caries in the permanent dentition in comparison to being female. The Nagelkerke $R$-square value for the model was 0.067 . 


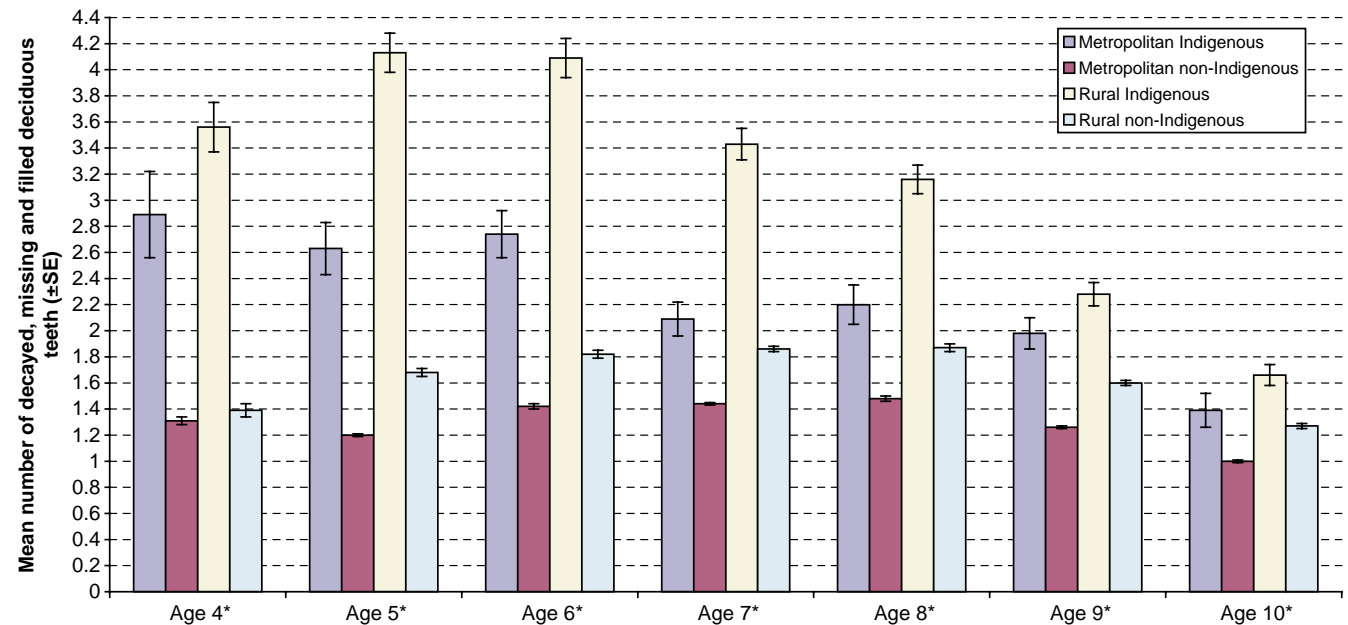

Figure 4 Mean Number of Decayed, Missing and Filled Deciduous Teeth of 4- to 10-Year-Old Indigenous and Non-Indigenous Children by Residential Location. ${ }^{*} p<0.05$. 


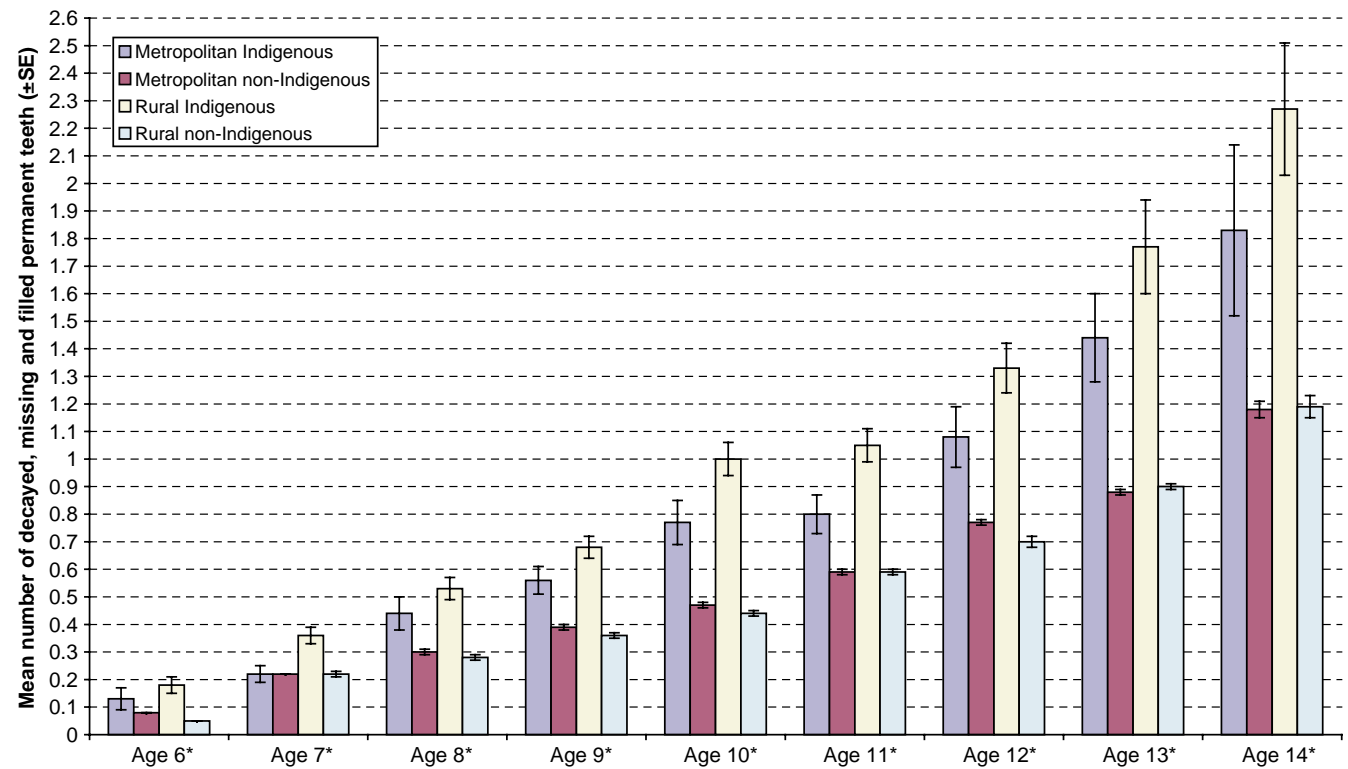

Figure 5 Mean Number of Decayed, Missing and Filled Permanent Teeth of 6- to 14-Year-Old Indigenous and Non-Indigenous Children by $₹$ Residential Location. ${ }^{*} p<0.05$. 
Table 3 Logistic Regression Model ${ }^{\text {a }}$ for Presence of Caries in Deciduous Teeth (4-10 Year Olds)

\begin{tabular}{lccc}
\hline & Standardised $B$ & SE & Odds ratio $(95 \% \mathrm{CI})$ \\
\hline Aged 4-7 years & 0.486 & 0.008 & $1.63(1.60,1.65)$ \\
Male & 0.129 & 0.009 & $1.14(1.12,1.16)$ \\
Indigenous & 0.809 & 0.025 & $2.25(2.14,2.36)$ \\
Rural dwelling & 0.368 & 0.010 & $1.45(1.42,1.47)$ \\
Most disadvantaged & 0.361 & 0.010 & $1.44(1.41,1.46)$ \\
\hline
\end{tabular}

${ }^{\mathrm{a}}$ Model $\chi^{2}=5,189.79 ; \mathrm{df}=5 ; 62.6 \%$ correctly predicted.

\section{Discussion}

This cross-sectional investigation of a child sample from three Australian states and territories showed that, irrespective of age, sex, residential location or SES, Indigenous children had higher caries prevalence and severity than non-Indigenous children. The most socially disadvantaged Indigenous children had poorer oral health than Indigenous children who were less deprived and Indigenous children residing in rural locations had worse oral health than their metropolitan-dwelling Indigenous counterparts. The differentials between Indigenous and non-Indigenous dental disease experience were marked, with Indigenous children in the least socially disadvantaged categories frequently having worse oral health than non-Indigenous children in the most disadvantaged categories and rural Indigenous children having up to three and a half times the dental disease experience of rural-dwelling nonIndigenous children. The literature shows that Indigenous children in countries such as New Zealand, Canada and the USA also experience poorer oral health than their non-Indigenous counterparts (Jones et al. 1992; Caplan \& Weintraub 1993; Thomson 1993; Niendorff \& Jones 2000; Edelstein 2002; Lee \& Dennison 2004; Peressini et al. 2004).

Although our sample size was large, it is important to consider its representativeness when considering the study's merits. Our sample represented between onequarter and two-fifths of the total child population in New South Wales, South Australia and the Northern Territory, respectively (Table 1), but all children had been

Table 4 Logistic Regression Model $^{\mathrm{a}}$ for Presence of Caries in Permanent Teeth (6-14 Year Olds)

\begin{tabular}{lccc}
\hline & Standardised $B$ & SE & Odds ratio $(95 \%$ CI $)$ \\
\hline Aged 4-7 years & -1.309 & 0.015 & $0.27(1.26,0.28)$ \\
Male & -0.132 & 0.010 & $0.88(0.86,0.89)$ \\
Indigenous & 0.519 & 0.025 & $1.68(1.60,1.77)$ \\
Rural dwelling & 0.038 & 0.011 & $1.04(1.02,1.06)$ \\
Most disadvantaged & 0.292 & 0.011 & $1.33(1.31,1.37)$ \\
\hline
\end{tabular}

${ }^{\mathrm{a}}$ Model $\chi^{2}=11,329.40 ; \mathrm{df}=5 ; 80.9 \%$ correctly predicted. 
enrolled in a voluntary school dental or screening service. Children not partaking in such schemes (who were not included in our sample) may have arguably had higher dental disease experience and thus may have contributed substantially to our findings had they been included (Vargas \& Ronzio 2002; Siegal et al. 2004). This is particularly so in regards to Indigenous children (Thomson \& Ali 2003). The school dental and screening services required caregivers to provide informed written consent before their child could be examined, so it may have been that the recruiting strategies used to encourage enrolment were not culturally sensitive enough to motivate some Indigenous caregivers. This is in accordance with other health care services that aim to recruit minority children and their caregivers (Julion et al. 2000; Story et al. 2003; Fisher et al. 2004). Caregiver mobility in remote communities (both within and beyond community confines, respectively) may be marked and may have further restricted opportunities for consent to be obtained (NTGDHCS 2004). Given the limited time that mobile school dental service/screening clinics remain in some communities, time constraints may have also precluded Indigenous child enrolment and examination. By nature of the school dental and screening services provided, there were high numbers of children aged 5-12 years and fewer aged 4, 13 and 14 years, respectively, in our sample; meaning those in the peripheral age-groups were also under-represented. Such groups were included in our analyses for completion and to allow easier comparison with ERP data.

The role of residential location in Indigenous child oral health is recognised. Endean et al. (2004) found that remote Indigenous children had markedly higher dental disease levels in comparison with the general Australian child population, and among Indigenous populations in Canada and the USA, rural-dwelling children have been consistently found to have poorer oral health than those residing in urban areas (Jones et al. 1992; Caplan \& Weintraub 1993; Niendorff \& Jones 2000; Edelstein 2002; Peressini et al. 2004). School dental service provision to rural areas in Australia, including oral health education and promotion initiatives, varies depending upon location, logistical challenges and staff availability (NHC 2001). Remoteness additionally impinges on Indigenous children's general health (Hitchcock et al. 1987; Dugdale et al. 1994; Gracey 2000; Mackerras et al. 2003) which, following the life-course model, may have long-term impacts on oral health (Kuh \& Ben-Shlomo 1997). People in remote communities may have limited access to fresh food produce and, in areas where fresh food is available, competing priorities for limited family incomes, lack of nutritional knowledge by caregivers and lack of culturally appropriate information on healthy food may contribute to dietary choices being made that are not conducive to generating or maintaining health (AIHW 2004). Remote locations do not generally benefit from fluoridated water supplies, although in some areas (for example, central Australia) natural fluoride water levels are high (Endean et al. 2004). The efficacy of fluoride, particularly water fluoridation, in the prevention of dental caries is incontrovertible (Antunes et al. 2004; Wang et al. 2004). In contrast to metropolitan areas, the availability of fluoridated toothpaste and toothbrushes in remote communities is also inconsistent, and if available, may be 
three times the cost of those in urban stores (NHC 2001). Cultural factors concerning child autonomy and self-responsibility may have additionally played a role in our remote Indigenous child oral health outcomes (Diamond 2004).

It is interesting that, when SES was controlled for, Indigenous children had up to three times the dental disease experience of non-Indigenous children (Figures 4 and 5 ) which suggests there are factors contributing to the observed oral health disparities that are not explained by SES alone. This may be because the SEIFA Index of Relative Disadvantage was not a sensitive enough measure of SES for the purposes of our study; that is, the parameters of the tool did not adequately encompass the multitude of complex and interrelated SES factors unique to the Indigenous situation. Using the index in conjunction with other SES measures, for example, individual or householdlevel SES instruments, or using more culturally specific SES tools such as household size, number of children for whom income earners are financially responsible and access to dental services may have addressed these shortcomings. Some anthropologists and social geographers argue that the fundamental contributing factor in Indigenous/non-Indigenous child health disparities is the 'social history' of being Indigenous; a phenomenon not easily captured by even the most robust and culturally sensitive social determinant measures (Hunter 1993; Milner 1996; Saggers \& Gray 1998; Diamond 2004).

On a world scale, Australia boasts one of the finest records of general and oral health (WHO 2005). The health status of its Indigenous groups, however, is on a par with inhabitants of the poorest developing countries, with the estimated life expectancy of Indigenous Australians being similar to that of populations of Pakistan, Indonesia, Guatemala and Iran (Marmot 2005). Welfare dependence is high (in 2001, some $65.7 \%$ of Indigenous Australians were dependent upon welfare; ABS 2001c) and is recognised as contributing - some would argue fundamentallyto Indigenous Australians' disempowerment (Chavez et al. 2004; Ziersch et al. 2005). Following these tenets, it could be that factors concerning the social history of Indigenous people contribute more to oral health outcomes than SES per se, which could explain why Indigenous children had worse oral health than non-Indigenous children in our study even when social disadvantage (as measured by the SEIFA Index of Disadvantage) was accounted for.

To further explore the role of SES in Indigenous oral health, it has been argued that it is not poverty in absolute terms that determines health, but relative poverty, that is, poverty in relation to other societal members (Pattussi et al. 2001; Marmot 2005). This has been illustrated by countries or states with relatively poor populations, but negligible income differences between population subsets, having good health (for example, China and the state of Kerala in India) and countries with relatively wealthy populations, but marked income differentials between population groups, having substantial health disparities (for example, Indigenous and non-Indigenous Australians). According to Marmot (2005), it is not because Indigenous Australians are materially poor that they have poor health, but because they are a socially excluded minority within their own country. Wooldridge (2000) acknowledged that 
Australia's 'single most spectacular failure as a nation has been in the area of Aboriginal and Torres Strait Islander health', which was suggested by Thomson (2003) as being largely due to the ongoing impacts of colonisation, discrimination and marginalisation on the Indigenous population. This is supported by McIntyre and Menzies (2005), who assert that the inferior health status of Indigenous Australians is inextricably linked to their historical legacy, their ongoing social and economic disadvantage (including displacement from their homes, land and lifestyle) and psychosocial trauma (particularly in regards to child separation); factors not experienced by the majority of non-Indigenous Australians. Against this backdrop, it is perhaps unsurprising that Indigenous children in our study had poorer oral health than their non-Indigenous counterparts, and it may be that before Indigenous and non-Indigenous child oral health parity is reached, fundamental shifts in the political and societal paradigms that determine Indigenous social capital are necessary.

In summary, our findings show that Indigenous children in three Australian states and territories had consistently worse oral health than non-Indigenous children irrespective of age, sex, residential location or SES. The findings add to the collective knowledge of Indigenous child oral health and, as such, may encourage policy makers to implement more effective and relevant Indigenous child oral health strategies; initiatives that address up-stream factors as well as those more directly related to dental service provision, and oral health education and promotion. More research in this area is required to better understand the complexity of the relationship between Indigenous status and child oral health.

\section{Acknowledgements}

The authors are grateful to the New South Wales, South Australia and Northern Territory dental authorities and school dental services for their assistance and support in the collection of this research data.

\section{References}

ABS (Australian Bureau of Statistics) (2001a) Indigenous Profile 2001 Census of Population and Housing, Australian Government, Canberra.

ABS (2001b) Census of Population and Housing-Socio-economic Indexes for Areas, Australia, Australian Government, Canberra.

ABS (2001c) Census of Population and Housing 2001; Basic Community Profile, Australian Government, Canberra.

ABS (2003) The Health and Welfare of Australia's Aboriginal and Torres Strait Islander Peoples, 2003, Australian Government, Canberra.

AIHW (Australian Institute of Health and Welfare) (2004) Australia's Health 2004, AIHW, Canberra.

Antunes, J. L., Narvai, P. C. \& Nugent, Z. J. (2004) 'Measuring inequalities in the distribution of dental caries', Community Dentistry \& Oral Epidemiology, vol. 32, pp. 41-48.

Barrett, M. J. (1953) 'Dental observations on Australian Aborigines, Yuendumu, Central Australia, 1951-52', Australian Journal of Dentistry, vol. 57, pp. 27-38. 
Barrett, M. J. \& Williamson, J. J. (1972) 'Oral health of Australian Aborigines: survey methods and prevalence of dental caries', Australian Dental Journal, vol. 32, pp. 37-50.

Bourke, C., Baima, D., Allister, J. \& Spencer, A. J. (1999) 'Caries experience of aboriginal children in South Australia', Journal of Dental Research, vol. 78, pp. 951.

Broome, R. (2002) Aboriginal Australians, 3rd edn, Allen \& Unwin, Melbourne, pp. 57-65.

Caplan, D. J. \& Weintraub, J. A. (1993) 'The oral health burden in the United States: a summary of recent epidemiologic studies', Journal of Dental Education, vol. 57, pp. 853-862.

Chavez, R., Kemp, L. \& Harris, E. (2004) 'The social capital:health relationship in two disadvantaged neighbourhoods', Journal of Health Services Research Policy, vol. 9, pp. 29-34.

Diamond, J. (2004) Collapse: How Societies Choose to Fail or Succeed, Viking Books, Los Angeles, pp. $12-18$.

Dugdale, A. E., Muller, M. \& Alsop-Shields, L. (1994) 'Patterns of weight growth in aboriginal children on Queensland communities', Journal of Paediatric Child Health, vol. 30, pp. 55-58.

Edelstein, B. L. (2002) 'Disparities in oral health and access to care: findings of national surveys', Ambulatory Pediatrics, vol. 2, pp. 141-147.

Endean, C., Roberts-Thomson, K. \& Wooley, S. (2004) 'Anangu oral health: the status of the Indigenous population of the Anangu Pitjantjatjara lands', Australian Journal of Rural Health, vol. 12, pp. $99-103$.

Fisher, E. B., Strunk, R. C., Sussman, R. C., Sykes, R. K. \& Walker, M. S. (2004) 'Community organization to reduce the need for acute care for asthma among African American children in low-income neighborhoods: the Neighborhood Asthma Coalition', Pediatrics, vol. 114, pp. $116-123$.

Gracey, M. (2000) 'Historical, cultural, political, and social influences on dietary patterns and nutrition in Australian Aboriginal children', American Journal of Clinical Nutrition, vol. 72, pp. $1361-1367$.

Hitchcock, N. E., Gracey, M., Maller, R. A. \& Spargo, R. M. (1987) 'Physical size of 1887 aboriginal schoolchildren in the Kimberley region', Medical Journal of Australia, vol. 146, pp. 415-419.

Hunter, E. (1993) Aboriginal Health and History: Power and Prejudice in Remote Australia, Cambridge University Press, Cambridge, pp. 162-169.

Jones, D. B., Schlife, C. M. \& Phipps, K. R. (1992) 'An oral health survey of Head Start children in Alaska: oral health status, treatment needs, and cost of treatment', Journal of Public Health Dentistry, vol. 52, pp. 86-93.

Julion, W., Gross, D. \& Barclay-McLaughlin, G. (2000) 'Recruiting families of color from the inner city: insights from the recruiters', Nursing Outlook, vol. 48, pp. 230-237.

Kailis, D. G. (1971a) 'Dental conditions observed in Australian Aboriginal children resident in Warburton and Cundeelee mission, Western Australia', Australian Dental Journal, vol. 16, pp. $44-52$.

Kailis, D. G. (1971b) 'Prevalence of dental caries in Australian Aboriginal children resident in Carnarvon, Western Australia', Australian Dental Journal, vol. 16, pp. 109-115.

Kuh, D. \& Ben-Shlomo, Y. (1997) A Life Course Approach to Chronic Disease Epidemiology, Oxford University Press, Oxford, pp. 3-14.

Lee, M. \& Dennison, P. J. (2004) 'Water fluoridation and dental caries in 5- and 12-year-old children from Canterbury and Wellington', New Zealand Dental Journal, vol. 100, pp. 10-15.

Mackerras, D. E., Reid, A., Sayers, S. M., Singh, G. R., Bucens, I. K. \& Flynn, K. A. (2003) 'Growth and morbidity in children in the Aboriginal Birth Cohort Study: the urban-remote differential', Medical Journal of Australia, vol. 178, pp. 56-60.

Marmot, M. (2005) 'Social determinants of health inequalities', The Lancet, vol. 365, pp. 10991104.

McIntyre, P. B. \& Menzies, R. I. (2005) 'Immunisation: reducing health inequality for Indigenous Australians', Medical Journal of Australia, vol. 182, pp. 207-208. 
Milner, G. R. (1996) Palaeopathology of Aboriginal Australians: Health and Disease Across a HunterGatherer Continent, Society for American Archaeology, Chicago, pp. 13-21.

NHC (Nganampa Health Council) (2001) Dentistry in Remote Aboriginal Communities, Nganampa Health Council, Alice Springs.

Nicolau, B., Marcenes, W., Bartley, M. \& Sheiham, A. (2003) 'A life course approach to assessing causes of dental caries experience: the relationship between biological, behavioural, socioeconomic and psychological conditions and caries in adolescents', Caries Research, vol. 37, pp. 319-326.

Niendorff, W. J. \& Jones, C. M. (2000) 'Prevalence and severity of dental caries among American Indians and Alaska Natives', Journal of Public Health Dentistry, vol. 60, pp. 243-249.

NTGDHCS (Northern Territory Government Department of Health and Community Services) (2004) 'Aboriginal health in the Northern Territory', in DHCS Annual Report 2003/2004, Northern Territory Government, Darwin.

Pattussi, M. P., Marcenes, W., Croucher, R. \& Sheiham, A. (2001) 'Social deprivation, income inequality, social cohesion and dental caries in Brazilian school children', Social Science \& Medicine, vol. 53, pp. 915-925.

Peressini, S., Leake, J. L., Mayhall, J. T., Maar, M. \& Trudeau, R. (2004) 'Prevalence of early childhood caries among First Nations children, District of Manitoulin, Ontario', International Journal of Paediatric Dentistry, vol. 14, pp. 101-110.

Saggers, S. \& Gray, D. (1998) Aboriginal Health and Society: The Traditional and Contemporary Aboriginal Struggle for Better Health, Allen \& Unwin, Melbourne, pp. 37-45.

Schamschula, R. G., Cooper, M. H., Adkins, B. L., Barmes, D. E. \& Agus, H. M. (1980) 'Oral conditions in Australian children of Aboriginal and Caucasian descent', Community Dentistry \& Oral Epidemiology, vol. 8, pp. 365-369.

Siegal, M. D., Yeager, M. S. \& Davis, A. M. (2004) 'Oral health status and access to dental care for Ohio head start children', Pediatric Dentistry, vol. 26, pp. 519-525.

Story, M., Sherwood, N. E., Obarzanek, E., Beech, B. M., Baranowski, J. C., Thompson, N. S., Owens, A. S., Mitchell, M. \& Rochon, J. (2003) 'Recruitment of African-American preadolescent girls into an obesity prevention trial: the GEMS pilot studies', Ethnicity \& Disease, vol. 13 , pp. $78-87$.

Tennant, M., Namjoshi, D., Silva, D. \& Codde, J. (2000) 'Oral health and hospitalisation in Western Australian children', Australian Dental Journal, vol. 45, pp. 204-207.

Thomson, N. (2003) 'Responding to our spectacular failure', in The Health of Indigenous Australians, ed. N. Thomson, Oxford University Press, Melbourne, pp. 488-505.

Thomson, N. \& Ali, M. (2003) 'Births, deaths and hospitalisation', in The Health of Indigenous Australians, ed. N. Thomson, Oxford University Press, Melbourne, pp. 44-74.

Thomson, W. M. (1993) 'Ethnicity and child dental health status in the Manawatu-Wanganui Area Health Board', New Zealand Dental Journal, vol. 89, pp. 12-14.

Vargas, C. M. \& Ronzio, C. R. (2002) 'Relationship between children's dental needs and dental care utilization: United States, 1988-1994', American Journal of Public Health, vol. 92, pp. 18161821.

Wang, B., Zheng, B., Zhai, C., Yu, G. \& Liu, X. (2004) 'Relationship between fluorine in drinking water and dental health of residents in some large cities in China', Environmental International, vol. 30, pp. 1067-1073.

Wooldridge, M. (2000) Launch of Australia's Health 2000 (media release). Available at: http:// www.health.gov.au/internet/wcms/Publishing.nsf/Content/health-mediarel-yr2000-mwmwsp200622.htm (accessed 29 June 2005).

WHO (World Health Organisation) (2005) Australia. Available at: http://www.who.int/countries/ aus/en/ (accessed 29 June 2005).

Ziersch, A. M., Baum, F. E., Macdougall, C. \& Putland, C. (2005) 'Neighbourhood life and social capital: the implications for health', Social Science \& Medicine, vol. 60, pp. 71-86. 